\title{
Exploring Warning Messages On Conditional Principles \& Predicting Social Behavior
}

Yoon C. Cho, KDI School of Public Policy and Management, Korea Jihoon Rim, KDI School of Public Policy and Management, Korea

\begin{abstract}
A wide variety of alcohol warning (or moderation) messages, as integrated communication tools, have been designed to reduce or moderate consumer attitudes toward alcohol consumption. The aim of this study is to explore the relationship between alcohol warning messages and alcohol consumption attitudes or behavior. In particular, this study investigates the effects of alcohol warning messages on consumer attitudes, subjective norms, intentions to switch alcohol consumption, and eventual behavioral change, by applying an extended Fishbein model. Further, these effects are based on types of messages examined by qualitative research, such as 1) positive or negative reinforcement warnings, 2) one-sided vs. two-sided warnings, and 3) self-vs. otherrelated warnings.
\end{abstract}

This paper conducted both qualitative and quantitative researches. Results of quantitative researches from surveys are measured by statistical analyses using chi-square, factor, and regression analysis. The results indicate that alcohol warning messages positively affected consumer attitudes toward reduction or moderation of alcohol consumption and that different types of ads produced different results. This study provides managerial implications for alcohol warning and advertising-related policies.

Keywords: Alcohol Warning Messages; Attitudes; Subjective Norms; Intentions; Extended Fishbein Model

\section{INTRODUCTION}

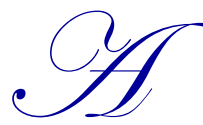

previous study by Mayer, Smith, and Scammon (1991) identifies warnings as an appealing policy tool because of the relatively low cost and consistency with individual freedom of choice. Warning messages have been designed in a wide range of forms for different purposes and using numerous criteria (Stewart and Martin, 1994) for issues of societal concern regarding consumer products. Studies on warning messages aim to gain publicity and have been examined from perspectives such as psychological principles (Cuniz, 1981), cognitive responses to labels (Bettman, Payne, and Staelin, 1986; Clark and Brock, 1994; Hilton, 1993) and believability of and attitudes toward messages (Andrews, Netemeyer, and Durvasula, 1990). Stewart and Martin (1994) stated that the number of warnings on products has grown precipitously in the last two decades, with increasing societal concern about the hazards of using and consuming various types of products and commodities. Smith (1990) also stated that the use of warnings may become increasingly common, even in advertisements. Issues concerning warning messages have gained more attention since the 1990s, as the U.S. federal government has mandated warning labels for beer, wine, and other types of liquors since November 1989 (Snyder and Blood, 1991). Various studies have considered the effectiveness of warning labels on products, such as alcoholic beverages, cigarettes, and medications (Mayer, Smith, and Scammon, 1991), the awareness level about warning messages (Mayer, Smith, and Scammon, 1991), and risk perception and behavioral change (Hilton, 1993). Studies have examined warning labels which have been an increasingly popular plan for alcohol policy and are considered as the most important ways to reduce social cost (Wilkinson and Room, 2009). Studies have discussed creating warning labels (Ross, 1981), warnings on product usages (Smith, 1990), cognitive considerations in designing effective 
labels (Bettman, Payne, and Staelin, 1986), and evaluating the impact of warning messages (Mayer, Smith, and Scammon, 1991; Mazis, Morris, and Swasy, 1991; Sydner and Blood, 1991; Graves, 1993; Torres, Sierra, and Heiser, 2007). While previous research has mentioned various aspects, definitions, usages, and the effectiveness of warning messages in various fields of product/service/public issue, the purpose of this study is to explore the effectiveness of warning messages by applying a framework concerning the effectiveness of alcohol warning messages on conditional principles (Ajzen and Fishbein, 1980) and warning contents.

By applying an extended Fishbein model (Ajzen and Fishbein 1980), this study examines how alcohol warning messages affect a consumer's attitudes, subjective norms, and intentions and eventually cause behavioral change. To explore this issue, both qualitative and quantitative research has been conducted. In particular, this study investigated the following research questions: 1) How do attitude estimates concerning reduction or moderation of alcohol consumption, such as behavioral beliefs and evaluations, affect differential attitudes' toward alcohol warning messages after viewing alcohol warning messages?, 2) How do estimates of subjective norms concerning reduction or moderation of alcohol consumption, such as normative beliefs and motivations to comply, affect differential subjective norms (i.e., attitudes toward alcohol warning messages based on subjective norms) after viewing alcohol warning messages?, 3) How do differential attitudes toward alcohol warning messages affect differential intention to switch alcohol consumption?, 4) How do differential subjective norms affect differential intention to switch alcohol consumption?, and 5) How does differential intention to switch alcohol consumption affect behavioral change to reduce or moderate alcohol consumption? The proposed effects are also measured based on types of warnings focusing on different issues, such as 1) positive vs. negative reinforcement messages, 2) onesided or two-sided messages, and 3) self- vs. other-related messages.

\section{HYPOTHESES DEVELOPMENT}

Cobuild (2001) stated that "if you warn someone about something, such as a possible danger or problem, you tell them about it so that they are aware of it" or "if you warn someone not to do something, you advise them not to do it so that they can avoid possible danger, harm/caution (Doubleday, 1975) or punishment." Alcohol warnings studies have focused on issues, such as "awareness of any possible danger" and "avoidance of possible problem" (Cobuild, 2001), "warnings, product instructions, and more general information about safety" (Stewart and Martin 1994), and magnitude of the related risk and how to avoid the related risk (Ross, 1981). Torres, Sierra, and Heiser (2007) stated that one of reasons for conveying warnings is for altruistic purposes, which means that warnings are created "to inform consumers and help generate a safe consumer response toward a product." With a behavioral perspective, Wogalter and Laughery (1996) suggested that the purpose of warnings includes informing people so they appreciate potential hazards and changing behavior to redirect people away from performing unsafe acts. In line with this, the ultimate purpose of warnings is to reduce or eliminate behavior regarded as objectionable (Stewart and Martin, 1994).

Alcohol warnings have diverse forms, such as pictorials, messages, moving pictures, labels, etc. The range of alcohol warnings has broadened into diverse alcohol moderation advertisements, simulation tests, campaigns, various programs, games, etc. Stewart and Martin (1994) stated that different types of warnings make different assumptions about both the intended audience and the effects of the warnings. Warning message dimensions are addressed (Stewart and Martin, 1994) by classifying message type (e.g., information on product contents, product effects, or specific prohibitions), target (e.g., specified vs. unspecified), and length (e.g., short vs. long). Wilkinson and Room (2009) suggested that alcohol warning labels or signs may take several forms, including 1) information about the contents or composition of the alcoholic beverage, 2) health-oriented alcohol warnings, statements or claims, and 3) locations and formats for alcohol warning signs. Toress, Sierra, and Heiser (2007) largely divided the alcohol warnings into two forms - on-product warnings (e.g., alcoholic bottle label) and off-product warnings (e.g., 'drink responsibly' print advertisements). This study conducted qualitative research to classify types of warning messages, in particular alcohol warning messages. About sixty studies that address the warning messages about alcoholic beverages were reviewed in addition to websites, including those of private and public organizations and search engines. After analysis of the warning messages, the following classification types of warning messages emerged: 1) positive reinforcement vs. negative reinforcement, 2) one-sided vs. two-sided, and 3) self-related issues vs. other-related issues. Figure 1 summarizes the framework of the effectiveness of alcohol warning messages on different types of warning messages. 


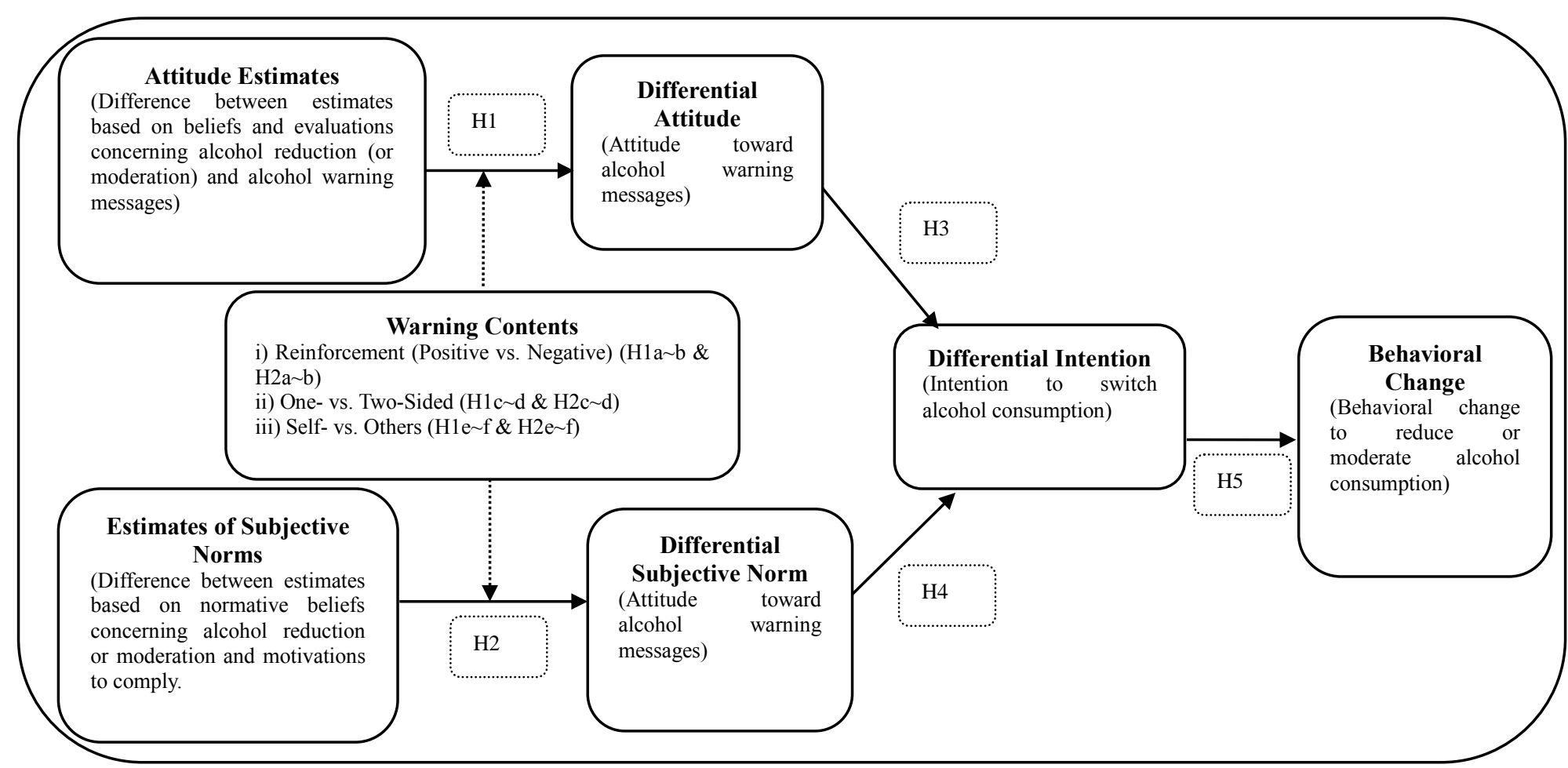

Figure 1: A Framework of the Effectiveness of Alcohol Warning Messages on Conditional Principles (Modified from Ajzen and Fishbein, 1980) - - - T The Effects of Different Types of Warning Messages

$\longrightarrow$ Stable Theoretical Relations Linking Beliefs to Behavior 
Many studies explored the effectiveness of alcohol warning messages based on theories and models, including the models from the field of social behavior. Theories such as social contact theory (Toress, Sierra, and Heiser, 2007), persuasive communication theory (Andrews, Netemeyer, and Durvasula, 1990; Bettman, Payne, and Staelin, 1986; Petty and Cacioppo, 1986), and reactance theory (Skurnik, Yoon, Park, and Schwarz, 2005; Stewart and Martin, 1994; Synder and Blod, 1991; Feingold and Knapp, 1977) have been adopted for alcohol warningrelated studies. Social contact theory supports measurements of the relationships between company acts, company brands, and customer perceptions, attitudes, and decisions (Toress, Sierra, and Heiser, 2007). Social contact theory also suggests that through this moral framework, researchers can measure customers' attitudes toward companies' intentions of publishing warning messages in various ways (Toress, Sierra, and Heiser, 2007). Previous researchers also applied persuasive communication theory to study warning-related messages, particularly to develop the effectiveness of warning information by considering believability and attitudes toward warning labels (Andrews, Netemeyer, and Durvasula, 1990; Bettman, Payne, and Staelin, 1986; Petty and Cacioppo, 1986). Similarly, Bettman Payne, and Staelin (1986) posited that designers may predict the effectiveness of a particular format of warnings more accurately by grasping how customers process information, while Petty and Cacioppo (1986) argued that relatively strong message persuasion may not be effective, since customers could perceive it as 'unbelievable.' Reactance theory (Skurnik, Yoon, Park, and Schwarz, 2005; Stewart and Martin, 1994; Synder and Blod, 1991) explains that the boomerang effect of warnings can also explain the effectiveness of warning messages through discussions on repeated exposures to the same messages, intensified levels of messages, perceived risk by societal groups (Taylor, 1976), and motivational states that may seem to threaten freedom (Clee and Wicklund, 1980). The hierarchy of effects model (O'Shaughnessy and O'Shaughnessy, 2007; Scammon, 1991; Friedmann, 1988) explains the effects of certain mental stages, such as attention to warning messages and processing of warning messages, on behavioral intention and behavior (Stewart and Martin, 1994).

The health-belief model also suggests that a consumer may be very likely to take action to keep away from a disease if he believes that 1) he is personally susceptible to the disease, 2) the occurrence of the disease would have at least moderately severe negative consequences on some aspect of his life, and 3) taking a particular action would be beneficial by reducing his susceptibility (Rosenstock, 1974, in Azjen and Fishbein, 1980). So, effective messages would stress the negative consequences caused by continued drinking, suggest how this action could be avoided, and recommend an alternative action (Azjen and Fishbein, 1980). Wilkinson and Room (2009) stated that positive health claims were common on alcoholic beverage containers and in alcoholic beverage advertising in the past (e.g., "Good for you" by Guinness). In developing countries, there are still positive health claims in alcoholic beverage advertising (Jernigan, 1997), but in the U.S. and most other developed countries, positive health claims in advertising are not allowed or are discouraged (Wilkinson and Room, 2009). Thus, most health claims on alcoholic beverage containers and in beverage advertising are negative health claims in developed countries such as 1) Warning: Excessive consumption of alcohol may cause liver cirrhosis or liver cancer and, especially women who drink while they are pregnant, increase the risk of congenital anomalies; 2) Red light of health! This is a result from wrong alcohol consumption habit; and 3) Abuse of this product is hazardous to your health. Like 1) and 3), many countries have "mandated health-related messages on alcoholic beverage containers (Wilkinson and Room, 2009). Finally, Malouff et al. (1993) stated that "the conspicuousness of health warnings on alcohol containers tends to influence their possible effectiveness."

\subsection{The Effectiveness of Attitude Estimates on Attitudes toward Alcohol Warning Messages}

Attitude is defined as a lasting, general evaluation of objects, or issues (Solomon, 2008) determined by the set of salient beliefs that one holds about performing particular behaviors (Ajzen and Fishbein, 1980). Prior studies (e.g., Ajzen and Fishbein, 1980) have shown that evaluating the consequences of attitude estimates, such as attitudes toward particular brands/messages/products/services and following behavior as an outcome, is crucial to exploring attitudes toward the behavior. Applying Ajzen and Fishbein's (1980) attitude estimates suggests that the behavior will lead to positive consequences and bring about a favorable attitude toward alcohol reduction or moderation. This study examined the difference between attitude estimates, based on beliefs and evaluations concerning alcohol reduction (or moderation) and alcohol warning messages. As Ajzen and Fishbein (1980) addressed the effects of attitude estimates on behavioral beliefs and outcome evaluations, this study applied both behavioral beliefs and evaluations of alcohol reduction or moderation habit and beliefs and evaluations toward alcohol warning messages. 
This study hypothesized the following relationship between attitude estimates concerning reduction or moderation of alcohol consumption and alcohol warning messages and differential attitudes toward alcohol warning messages.

H1: Attitude estimates concerning reduction or moderation of alcohol consumption messages positively affect differential attitude after viewing alcohol warning messages.

Further, this paper measures whether one's attitude toward alcohol warning messages is affected positively or negatively after viewing different types of alcohol warning messages. To examine the impact of attitude estimates on differential attitudes toward alcohol warning messages, different types of alcohol warning messages, one- or twosided with a positive or negative voice, were examined. This study also analyzed message contents based on whether the messages were aimed at the self- and other-related issues. As a result of reviewing prior qualitative research, the effects of warning messages were classified as: 1) positive vs. negative reinforcement, 2) one- vs. two-sided warning messages, and 3) self- vs. others-related issues.

\subsubsection{Alcohol Warning Messages Addressing Positive and Negative Reinforcement}

Various researchers (Allen and Madden, 1985; Bierley et al., 1985; Stuart et al., 1987; McSweeney and Bierley, 1984; Grossman and Till, 1998) have applied conditioning models in consumer behavior fields, including the effects of advertising. However, few have applied a conditioning model in studies of issues related to warning messages. There are two types of conditioning models; namely, the classical conditioning model and the operant conditioning model (O'Shaughnessy and O'Shaughnessy, 2007). This study applied the operant conditioning model to explore the effectiveness of alcohol warning messages. The operant conditioning model was developed by Skinner (1953). The main concept of this model is that all living organisms behave spontaneously and whenever this behavior is reinforced, the chances they will repeat the behavior are increased (O'Shaughnessy and O'Shaughnessy, 2007). O'Shaughnessy and O'Shaughnessy (2007) stated that positive reinforcement, which encourages a repetition of the buying action, occurs when the customer purchases any specific product and the result is pleasant, while negative reinforcement comes whenever removing something negative is pleasurable. Skinner (1953)'s theory was that operant conditioning controls one's behavior by manipulating these reinforcements. This study classified alcohol warning messages into positive reinforcement; namely, alcohol warning messages that address positive aspects, and negative reinforcement; namely, alcohol warning messages that address negative aspects. The following warning messages were adopted as examples of positive reinforcement: 1) "cool drinker: cool, nice, wise, responsible, able to drink in moderation, no drunken driving" and 2) "Please fill a glass properly. Your alcohol moderation behavior makes us smile with joy." On the other hand, the following warning messages were adopted as examples of negative reinforcements: 1) Your life insurance may have to pay out after only one glass of an alcoholic beverage" and 2) "Almost half of all adult drowning deaths involve alcohol." This study hypothesized that the effects of attitude estimates on differential attitude differ with types of reinforcement.

H1a b: The effects of attitude estimates on differential attitude vary depending on whether alcohol warnings address positive or negative reinforcement.

\subsubsection{One-Sided and Two-Sided Alcohol Warning Messages}

This study applied the concept of one-sided and two-sided advertising to explore the effectiveness of alcohol warning messages. Advertisers normally make efforts to promote their brands or products as superior to competing brands or products on determinant attributes (Aaker and Myers, 1987; Ogivly, 1985). However, a study by Pechmann (1992) suggested that consumers tend to be skeptical of ad claims and may not perceive the brands as favorably as was intended by the advertisers. Studies have classified advertisements into either one- or two-sided. Based on prior research (Kamins and Assael, 1987), a one-sided appeal in advertising only makes claims that are supportive of the product or brand while a two-sided appeal, in addition to presenting positive claims about important attributes, down-grades or limits product or brand performance claims on attributes of minor significance to the consumer so as to establish credibility without deterring purchase. Researchers have argued that two-sided advertisements can enhance the credibility of the claims (Settle and Golden, 1974; Smith and Hunt, 1978) because two-sided advertisements include not only the advantages of the brands but also their shortcomings (Pechmann, 1992). Studies (Kamins and Assael, 1987; Smith and Hunt, 1978; Stayman, Hoyer, and Leon, 1987) have also 
addressed that two-sided ads tend to be viewed as more credible than their one-sided counterparts. In addition, Pechmann (1992) posited that two-sided advertisements were more effective than one-sided advertisements only when negatively correlated attributes were featured. This study hypothesized that one-sided advertisements giving alcohol warning messages have different impacts than two-sided advertisements giving two-sided alcohol warning messages.

H1c d: The effects of attitude estimates on differential attitude vary depending on whether alcohol warnings use one- or two-sided messages.

\subsubsection{Alcohol Warning Messages That Address Self-and Other-Related Issues}

The definition of self-concept is the beliefs that a person holds about his or her own attributes and how he or she evaluates these qualities (Solomon, 2008). Self-concept denotes the totality of the individual's thoughts and feelings having reference to the individual as an object (Rosenberg, 1979; Sirgy, 1982). According to Solomon (2008), the self-concept significantly affects consumer behavior because self-concepts are reflections of consumers' attitudes toward themselves. Solomon (2008) also stated that products often play a pivotal role in defining the selfconcept as consumers choose to buy many products because they think they fit their personalities. On the other hand, this study considered warning messages that focus on the concepts of subjective norms and social pressure (Ajzen and Fishbein, 1980) as other-related rather than self-related.

This study applied the concepts of self and others to investigate the effectiveness of alcohol warning messages. Self, in this study, means that a warning message which addresses self-related issues and others means a warning message that addresses other-related issues. For example, alcohol warning messages, such as "Drunken driving! You can die with even one glass of alcoholic beverage" is considered addressing self-related issues because this warning message focuses on the consequences caused by your drinking. On the other hand, alcohol warning messages, such as "Your excessive drinking can cause pain for somebody" addresses other-related issues because this warning message focuses on the effects of your drinking on other people. This study hypothesized that the alcohol warnings addressing self-related issues have different impacts than self-related warnings.

H1e f: The effects of attitude estimates on differential attitude vary depending on whether alcohol warnings address self-related or others-related issues.

\subsection{The Effectiveness of Estimates of Subjective Norms on Differential Subjective Norms}

According to Solomon (2008), the definition of a subjective norm is an additional component to the multiattribute attitude model that accounts for the effects of what we believe other people think we should do. Subjective norms are formed based on normative beliefs instead of behavioral beliefs (Azjen and Fishbein, 1980). For example, a behavioral belief, such as that "I would have better health if I reduced or moderated my alcohol consumption", is not considered a normative belief, but one that "An important person near me (such as a family member) thinks I should reduce or moderate my alcohol consumption" is considered a normative belief. Subjective norms are formed based on the total set of salient normative beliefs, each weighted by motivation to comply (Ajzen and Fishbein, 1980). Estimates of subjective norms are the differences between estimates based on normative beliefs concerning alcohol reduction or moderation and the motivation to comply. According to Ajzen and Fishbein (1980), the estimates of subjective norms are related to normative beliefs concerning behavior and motivations to comply; so this study examined normative beliefs concerning alcohol reduction or moderation, and motivation to comply. With respect to the differential subjective norm shown in Figure 1, this study examined attitudes toward alcohol warning messages based on subjective norms. To explore the effectiveness of estimates of subjective norms on differential subjective norm (i.e., attitude toward alcohol warning messages based on subjective norm), eight different types of alcohol warning messages were also examined.

In this study, the basic focus of the second hypothesis is to measure how estimates of subjective norms concerning alcohol reduction or moderation of alcohol consumption, such as normative beliefs and motivations to comply, affect differential subjective norms (i.e., attitudes toward alcohol warning messages based on subjective norms). 
H2: Estimates of subjective norms concerning reduction or moderation of alcohol consumption positively affect differential subjective norms after viewing alcohol warning messages.

H2a b: The effects of estimates of subjective norms on differential subjective norms vary depending on whether alcohol warnings address positive reinforcement or negative reinforcement.

H2c d: The effects of estimates of subjective norms on differential subjective norms vary depending on whether alcohol warnings address one-sided messages or two-sided messages.

H2e $\mathbf{f}$ : The effects of estimates of subjective norms on differential subjective norms vary depending on whether alcohol warnings address self-related issues or other-related issues.

\subsection{The Effectiveness of Differential Attitude on Differential Intention}

To understand differential intention, the concept of behavioral intention needs to be reviewed. According to Ajzen and Fishbein (1980), one's intention is determined by one's attitude toward the behavior and by one's subjective norms. This intention is assumed to be "the immediate antecedents of actions." A measure of intention would not be an appropriate predictor of behavior at all times, however (Ajzen and Fishbein, 1980); that is to say, as the old expression has it, "the road to hell is paved with good intentions" - many factors could interfere with acting on the intended behavior (Solomon, 2008). Thus, the effectiveness of one's attitude and subjective norms on behavior is affected by one's behavioral intention. For example, even if a researcher knows that one intends to reduce or moderate alcohol consumption behavior, this may not represent a precise prediction of one's actual behavior. In this regard, Ajzen and Fishbein (1980) suggested that the longer the time interval is, the greater the likelihood is that events will occur which will produce changes in intentions. In this study, there was a limited interval between measuring behavioral intentions and observing actual behavior. As proposed in Figure 1, this study compared differential with intention to switch alcohol consumption. Based on this consideration, this study measures whether differential attitude affects differential intention positively. In particular, this study estimates whether one's attitude toward alcohol warning messages, which is formed by attitude estimates, affects the intention to switch alcohol consumption positively or not. To explore differential intention, eight different types of alcohol warning messages were also examined. Overall, the basic focus of this hypothesis is the relationship between differential attitude toward alcohol warning messages, which is formed by attitude estimates, and differential intention to switch alcohol consumption.

H3: There is a positive relationship between differential attitude and differential intention.

\subsection{The Effectiveness of Differential Subjective Norms on Differential Intention}

As stated by Ajzen and Fishbein (1980), behavioral intention is determined by one's attitude toward a behavior and by one's subjective norm. Ajzen and Fishbein (1980) suggested that, in most cases, people hold favorable attitudes toward behaviors their significant others think that they should perform, while negative attitudes toward behaviors their significant others think they should not perform. Sometimes the attitude toward particular behaviors may not be compliant with subjective norms, however (Ajzen and Fishbein 1980). For example, the differential attitude toward alcohol warning messages, which is formed from attitude estimates, may not be compliant with the differential subjective norms (i.e., attitudes toward alcohol warning messages based on subjective norms), which are formed from estimates of subjective norms depending on situations. Differential attitude toward alcohol warning messages can be more important in determining behavioral intention to switch alcohol consumption than differential subjective norm and vice versa. Thus, this paper explores which component is more important to determine the intention to switch alcohol consumption. In this study, the basic focus of the hypothesis is the difference between the effectiveness of differential attitude toward alcohol warning messages or intention to switch alcohol consumption and the effectiveness of differential subjective norms (i.e., attitudes toward alcohol warning messages based on subjective norm) on intention to switch alcohol consumption).

This study also measures whether differential subjective norms affect differential intention positively; that is to say, this paper estimates whether one's attitude toward alcohol warning messages based on subjective norm 
affects the intention to switch alcohol consumption positively or not. To explore the effectiveness of differential subjective norms on differential intention, different types of alcohol warning messages were also examined. In this study, the basic focus of the following hypothesis is the relationship between differential subjective norms (i.e., attitudes toward alcohol warning messages based on subjective norms) and differential intention to switch alcohol consumption.

H4: There is a positive relationship between differential subjective norm and differential intention.

\subsection{The Effectiveness of Differential Intention on Behavioral Change}

To understand behavioral change, the concept of behavior needs to be reviewed. Behavior is a consumer's actions with regard to an attitude or object (Solomon, 2008). Since there could be some gap between one's intention and behavior, researchers look for a consumer's past purchase behavior instead of looking at his or her intentions to predict his or her future behavior more effectively (Solomon, 2008). This study measures whether or not the differential intention to switch alcohol consumption positively affects behavioral change to reduce or moderate alcohol consumption. This may be a limitation of the study since there could be a gap between intention to switch alcohol consumption attitude and real action to reduce or moderate alcohol consumption.

H5: There is a positive relationship between differential intention and behavioral change.

\section{METHODOLOGY}

This study measures 1) the relationships between attitudes, subjective norms, differential intentions and behavioral change and perceptions of alcohol warning advertisements and 2) how the effectiveness is different depending on different types of alcohol warning advertisements. This study applied qualitative research in order to classify different types of warning messages. By using 56 prior studies published in well-known journals, this study conducted qualitative analysis in order to classify types of warning messages. Further, this study conducted quantitative research with combined formats of experimentation and survey to assess the differential effectiveness of alcohol warning messages. In addition, the study conducted a pilot test with 102 respondents and a main test with 500 respondents who have had exposure to and experience of drinking alcoholic beverages. Different types of warning messages were selected from various sources of integrated communication tools, such as TV, news, and magazine. Screen shots and captured pictures of different types of warning messages were displayed in experiments and survey. A pilot test for questionnaire items was conducted before the main test. A seven-point Likert scale was applied for each construct (e.g., 1 is" strongly disagree" and 7 is "strongly agree"). Random data collection was applied. These alcohol warning advertisements are: 1) alcohol warning messages that address positive and negative reinforcement, 2) alcohol warning messages that are one- or two-sided, and 3) alcohol warning advertisements that address self- and others. In order to measure the effects of different types of alcohol warning images, selections were made after reviewing around 100 alcohol warning advertisements. Most of them are pictorial advertisements, while some of them are screen shots from video advertisements. These different types of images were shown to the respondents twice during the survey to measure 1) overall perception of alcohol warning advertisements and 2) differential perception depending on the type of alcohol warning advertisement.

\section{DATA ANALYSIS}

\subsection{Data Analysis of Qualitative Research}

This study found that warning messages can be segmented into different types based on conditioning principles and different types of subjective norms. Qualitative research analysis found that 22 one-sided warning messages addressed positive reinforcement, 26 one-sided warning messages addressed negative reinforcement, and eight two-sided warning messages addressed both positive and negative reinforcement. In addition, the study found that 28 warning messages addressed self, while 10 warning messages addressed others, and 18 warning messages addressed both self and others. Of the 22 one-sided warning messages that addressed positive reinforcement, 11 addressed self, two addressed others, and nine addressed both self and others. Of the 26 one-sided warning messages that addressed negative reinforcement, 15 addressed self, six addressed others, and five addressed both self and 
others. Of the eight two-sided warnings that addressed both negative and positive reinforcement, two addressed self, two addressed others, and four addressed both self and others. All types of messages also segmented into public versus private. Of the 28 warning messages that addressed self, 22 warning messages were from the public sector and six were from private sectors. Among 10 warning messages that address others, nine warning messages are from the public sector and one is from the private sector. Based on these types of alcohol warning messages, content analysis was conducted using chi-square. Chi-square results $\left(X^{2}=31.23\right)$ showed that there are significant differences based on categories of message types - self, others, self \& others - and one-sided (positive and negative) and two-sided (significant at 5\%).

\subsection{Data Analysis of Quantitative Research}

\subsubsection{Demographics}

Of the 500 participants, $67.6 \%$ were male and $32.4 \%$ were female, and $50.1 \%$ were married while $48.9 \%$ were single. Of the 51 participants who were married, $75.0 \%$ had children while $25.0 \%$ did not have children. Educational backgrounds varied, with $2.0 \%$ of participants' having associate's degrees, $68.6 \%$ having bachelor's degrees, 22.5\% having graduate degrees, and 3.9\% having Ph.Ds. In addition, 90.2\% of respondents had a driver's license, $6.9 \%$ did not, and $2.9 \%$ did not answer. By age, $7.8 \%$ of respondents were $20-29,85.3 \%$ were $30-39$, and $3.9 \%$ were $40-49$. By occupation, $9.8 \%$ were students, $47.1 \%$ were businessmen, $6.9 \%$ were bankers, $1.0 \%$ were teachers, $2.0 \%$ were professors, $7.8 \%$ were non-profit organization workers, $2.9 \%$ were government officers, $11.8 \%$ were engineers, $4.9 \%$ were business owners, and $2.9 \%$ were housewives. Finally, $13.7 \%$ of respondents drank alcohol more than three times per week, $41.2 \%$ drank once or twice per week, and $45.1 \%$ drank less often, averaged over the last six months.

\subsubsection{Hypothesis Testing}

To analyze the proposed hypotheses, this study uses the results from the quantitative analyses such as factor and regression analyses. Factor scores and factor coefficients from factor analysis were used for regression analyses (Cho, 2010). Using principal components analyses as the extraction method and Varimax rotation methods with Kaiser Normalization, the most relevant data emerged (Cho, 2010). Factors turned out to be 1) attitude estimates of alcohol consumption and attitude toward alcohol warning messages, 2) differential attitudes toward alcohol warning messages, 3) estimates of subjective norms concerning reduction or moderation of alcohol consumption, 4) differential subjective norms: attitudes toward alcohol warning messages, 5) differential intention to switch alcohol consumption, and 6) behavioral change to reduce or moderate alcohol consumption. These factors are grouped as variables when eigenvalues are over 1.00 (Table 1). 
Table 1: Component Matrix - Factors That Affect Effectiveness of Alcohol Warning Messages on Conditional Principles

\begin{tabular}{|c|c|c|c|c|c|c|c|}
\hline \multicolumn{2}{|r|}{ Items } & \multicolumn{6}{|c|}{ Component } \\
\hline $\begin{array}{l}\text { External } \\
\text { Factors }\end{array}$ & Scale Items & 1 & 2 & 3 & 4 & 5 & 6 \\
\hline Attitudes 1 & $\begin{array}{l}\text { I think alcohol warning messages alarm me to reduce or } \\
\text { moderate alcohol consumption. }\end{array}$ & .809 & & & & & \\
\hline Attitudes 2 & I think alcohol warning messages are effective and persuasive. & .791 & & & & & \\
\hline Attitudes 3 & $\begin{array}{l}\text { I am willing to reduce alcohol consumption due to the alcohol } \\
\text { warning messages. }\end{array}$ & .753 & & & & & \\
\hline Attitudes 4 & $\begin{array}{l}\text { I think the contents of alcohol warning messages are } \\
\text { informative and believable. }\end{array}$ & .627 & & & & & \\
\hline $\begin{array}{l}\text { Differential } \\
\text { Att } 1\end{array}$ & $\begin{array}{l}\text { Alcohol warning messages alarm me that my reduction or } \\
\text { moderation toward alcohol consumption attitude is important to } \\
\text { have more well-being related lifestyle. }\end{array}$ & & .898 & & & & \\
\hline $\begin{array}{l}\text { Differential } \\
\text { Att } 2\end{array}$ & $\begin{array}{l}\text { Alcohol warning messages alarm me to reduce or moderate } \\
\text { alcohol consumption. }\end{array}$ & & .866 & & & & \\
\hline $\begin{array}{l}\text { Differential } \\
\text { Att } 3\end{array}$ & $\begin{array}{l}\text { Alcohol warning messages alarm me that my reduction or } \\
\text { moderation toward alcohol consumption attitude is important to } \\
\text { improve my health condition. }\end{array}$ & & .857 & & & & \\
\hline $\begin{array}{l}\text { Differential } \\
\text { Att } 4\end{array}$ & $\begin{array}{l}\text { I feel that I need to reduce or moderate my alcohol consumption } \\
\text { by seeing those alcohol warning advertisements and messages. }\end{array}$ & & .843 & & & & \\
\hline $\begin{array}{l}\text { Differential } \\
\text { Att } 5\end{array}$ & $\begin{array}{l}\text { Alcohol warning messages strengthen my beliefs toward } \\
\text { alcohol reduction attitudes. }\end{array}$ & & .823 & & & & \\
\hline $\begin{array}{l}\text { Subjective } \\
\text { Norm } 1\end{array}$ & $\begin{array}{l}\text { If most people who are important to me decide to reduce or } \\
\text { moderate their alcohol consumption, I would support their } \\
\text { decision. }\end{array}$ & & & .799 & & & \\
\hline $\begin{array}{l}\text { Subjective } \\
\text { Norm } 2\end{array}$ & $\begin{array}{l}\text { If most people who are important to me have an alcohol } \\
\text { moderation attitude, I think I can more easily reduce or } \\
\text { moderate my alcohol consumption attitude. }\end{array}$ & & & .796 & & & \\
\hline $\begin{array}{l}\text { Subjective } \\
\text { Norm } 3\end{array}$ & $\begin{array}{l}\text { For me, the main reason why I drink alcoholic beverages is for } \\
\text { relationship with people who are important to me. }\end{array}$ & & & 639 & & & \\
\hline $\begin{array}{l}\text { Differential } \\
\text { Subjective } \\
\text { Norm } 1\end{array}$ & $\begin{array}{l}\text { If my family members or relatives have a positive attitude } \\
\text { toward alcohol warning messages, I think that I also would have } \\
\text { a positive attitude toward alcohol warning (moderation) } \\
\text { messages. }\end{array}$ & & & & .859 & & \\
\hline $\begin{array}{l}\text { Differential } \\
\text { Subjective } \\
\text { Norm } 2\end{array}$ & $\begin{array}{l}\text { Alcohol reduction (or moderation) attitude would help me to be } \\
\text { a more socially responsible person. }\end{array}$ & & & & .853 & & \\
\hline $\begin{array}{l}\text { Differential } \\
\text { Subjective } \\
\text { Norm } 3\end{array}$ & $\begin{array}{l}\text { After I perceive alcohol warning messages, at least, I consider } \\
\text { to reduce or to moderate my alcohol consumption for my } \\
\text { important people. }\end{array}$ & & & & .812 & & \\
\hline $\begin{array}{l}\text { Differential } \\
\text { Subjective } \\
\text { Norm } 4\end{array}$ & $\begin{array}{l}\text { After I perceive alcohol warning messages, at least, I consider } \\
\text { to reduce or to moderate my alcohol consumption not only for } \\
\text { myself but also for social obligatory. }\end{array}$ & & & & .792 & & \\
\hline Intention 1 & $\begin{array}{l}\text { I'm willingness to switch my alcohol consumption attitude by } \\
\text { seeing those alcohol warning (or moderation) advertisements } \\
\text { and messages. }\end{array}$ & & & & & .873 & \\
\hline Intention 2 & $\begin{array}{l}\text { I have a tendency to reduce or moderate drinking alcoholic } \\
\text { beverages when I see alcohol warning messages. }\end{array}$ & & & & & .843 & \\
\hline Intention 3 & I intend to reduce or moderate alcohol consumption attitude. & & & & & .822 & \\
\hline $\begin{array}{l}\text { Behavioral } \\
\text { Change } 1\end{array}$ & $\begin{array}{l}\text { I'll start to reduce or moderate my alcohol consumption } \\
\text { attitude. }\end{array}$ & & & & & & .870 \\
\hline $\begin{array}{l}\text { Behavioral } \\
\text { Change } 2\end{array}$ & $\begin{array}{l}\text { Above alcohol warning messages positively affect to switch my } \\
\text { alcohol consumption. }\end{array}$ & & & & & & .811 \\
\hline
\end{tabular}

This study applied analyses, such as regression analysis and analysis of variance (ANOVA). Table 2 provides the results of the regression analyses using factor scores for the effects of proposed factors, including attitude estimates, differential attitude, estimates of subjective norms, differential subjective norm, differential 
intention, and behavioral change. Overall, the results of the ANOVA on the effects of attitude estimates (belief and evaluations of effects on alcohol consumption) on differential attitude toward alcohol warning messages finds the models significant at the .01 level with $F=7.125$ ( $r$-square $=.304)$. On the effects of estimates of subjective norms on differential subjective norms, it finds the models significant at the .01 level with $F=8.859$ (r-square $=.213)$. In the case of the effects of differential attitude and intention, it finds the models significant at the .01 level with $F=$ 34.593 ( $r$-square $=.580$ ). In the case of effects of differential attitude and intention, it finds the models significant at the .01 level with $F=34.593(r$-square $=.580)$. In the case of differential subjective norms and intentions, it finds the models significant at the 0.01 level with $F=67.969$ ( $r$-square $=.579$ ), and in the case of effects of differential intention on behavioral change, it finds the models significant at the .01 level with $F=199.293$ ( $r$-square $=.666$ ). The results of the regression analysis found $p=.000(r$-square $=.304)$ for the effects of attitude estimates on differential attitude toward alcohol warning messages; therefore, Hypothesis 1 is accepted at alpha $=1 \%$. The results of the regression analysis found $p=.000(r$-square $=.213$ ) for the effects of estimates of subjective norms on differential subjective norms. Findings indicated that Hypothesis 2 is accepted at alpha $=1 \%$. The results of the regression analysis found $p=.000(r$-square $=.580)$ for the effects of differential attitude toward alcohol warning messages on differential intention to switch alcohol consumption. Results showed $p<.05$; therefore, Hypothesis 3 was accepted. Both effects of differential subjective norm to differential intention (H4) and effects of differential intention to behavioral change $(\mathrm{H} 5)$ are accepted at alpha $=1 \%(p=.000, r$-square $=.666)$.

Table 2: Summary of the Effects of Attitude Estimates, Differential Attitude, Estimates of Subjective Norms, Differential Subjective Norm, Differential Intention, and Behavioral Change

\begin{tabular}{|l|c|}
\hline \multicolumn{1}{|c|}{ Variable (Independent -> Dependent) } & Standardized Coefficient (t-value-Sig) \\
\hline Attitude Estimates -> Differential Attitude (H1) & $0.452(3.403 * * *)$ \\
\hline Estimates of Subjective Norms -> Differential Subjective Norm (H2) & $0.284\left(3.173^{* * *)}\right.$ \\
\hline Differential Attitude -> Differential Intention (H3) & $0.698\left(7.617^{* *}\right)$ \\
\hline Differential Subjective Norm -> Differential Intention (H4) & $0.656(10.057 * *)$ \\
\hline Differential Intention -> Behavioral Change (H5) & $0.816\left(14.117^{* * *)}\right.$ \\
\hline
\end{tabular}

*** Significant at 0.01 level (2-tailed); ** Significant at 0.10 level (2-tailed).

This study conducted additional factor analyses for effects such, such as: 1) positive and negative messages, 2) one- and two-sided messages, and 3) messages focusing on self and others. Based on the coefficients from factor analysis, this study measured the effects of attitude estimates on differential attitude toward alcohol warning messages that address positive and negative reinforcement (H1a b shown in Table 3 ). The results of the regression analysis were significant for the effects of attitude estimates on differential attitude toward alcohol warning messages that address both positive and negative reinforcement at alpha $=1 \%$. While both effects were significant, the degree of effect of negative reinforcement was slightly higher than positive reinforcement. The study also found that one-sided alcohol warning messages were slightly more effective than two-sided alcohol warning messages (H1c $\sim$ d shown in Table 3). The results of the regression analysis were significant for the effects of attitude estimates on differential attitude toward alcohol warning messages that address both one-sided and two-sided messages at alpha $=1 \%$. The results of the regression analysis were significant for the effects of attitude estimates on differential attitude toward alcohol warning messages that address self- or other-related issues, but slightly higher with otherrelated issues (H1e f shown in Table 3).

Table 3: Summary of the Effects of Attitude Estimates on Differential Attitudes Based on Types of Effects

\begin{tabular}{|c|c|c|}
\hline \multirow{2}{*}{ Variable (Independent -> Dependent) } & \multicolumn{2}{|c|}{ Standardized Coefficient ( $t$-value-Sig) } \\
\hline & H1a, c, \& e & H1b, d, \& f \\
\hline $\begin{array}{l}\text { Attitude Estimates -> Differential Attitude on positive or negative reinforcement } \\
(\mathrm{H} 1 \mathrm{a} \sim \mathrm{b})\end{array}$ & $0.446(3.594 * * *)$ & $0.525(4.445 * * *)$ \\
\hline $\begin{array}{l}\text { Attitude Estimates -> Differential Attitude on one-sided or two-sided message } \\
(\mathrm{H} 1 \mathrm{c} \sim \mathrm{d})\end{array}$ & $0.371(2.856 * * *)$ & $0.426\left(3.316^{* * *}\right)$ \\
\hline $\begin{array}{l}\text { Attitude Estimates -> Differential Attitude on Self - or Other - related issues } \\
(\text { H1e f) }\end{array}$ & $0.278(2.063 * *)$ & $0.355(2.712 * * *)$ \\
\hline
\end{tabular}

*** Significant at 0.01 level (2-tailed); ** Significant at 0.05 level (2-tailed)

Further, this study measured the effects of estimates of subjective norms on differential subjective norms that address positive and negative reinforcement (H2a b shown in Table 4). The results of the regression analysis 
were significant for the effects of estimates of subjective norms on differential subjective norms that address both positive and negative reinforcement at alpha $=1 \%$. The study found that alcohol warning messages that address negative reinforcement were slightly more effective than alcohol warning messages that address positive reinforcement. The results of the regression analysis were significant for the effects of estimates of subjective norms on differential subjective norm toward alcohol warning messages that address both one-sided and two-sided messages at alpha $=1 \%$. The study also found that one-sided alcohol warning messages were slightly less effective than two-sided alcohol warning messages (H2c $\sim$ d shown in Table 4). The results of the regression analysis were significant for the effects of estimates of subjective norms on differential subjective norm toward alcohol warning messages that address self- or other-related issues (H2e f shown in Table 4). The study also found that other-related issues were higher than self-related issues.

Table 4: Summary of the Effects of Subjective Norm on Differential Subjective Norms Based on Types of Effects

\begin{tabular}{|l|c|c|}
\hline \multicolumn{1}{|c|}{ Variable (Independent -> Dependent) } & Standardized Coefficient $(\boldsymbol{t}$-value-Sig) \\
\cline { 2 - 3 } & H2a, c, \& e & H2b, d, \& f \\
\hline $\begin{array}{l}\text { Estimates of Subjective Norms-> Differential Subjective Norm on positive or } \\
\text { negative reinforcement (H2a b) }\end{array}$ & $0.307(3.272 * * *)$ & $0.363(3.983 * * *)$ \\
\hline $\begin{array}{l}\text { Estimates of Subjective Norms-> Differential Subjective Norm on one-sided or } \\
\text { two-sided message (H2c d) }\end{array}$ & $0.284(2.913 * * *)$ & $0.301(3.107 * * *)$ \\
\hline $\begin{array}{l}\text { Estimates of Subjective Norms-> Differential Subjective Norm on Self - or } \\
\text { Others -related issues (H1e f) }\end{array}$ & $0.181(1.806 *)$ & $0.400(4.529 * * *)$ \\
\hline
\end{tabular}

*** Significant at 0.01 level (2-tailed); *Significant at 0.10 level (2-tailed)

\section{CONCLUSION}

\subsection{Discussion}

The model for this study measured diverse effectiveness of alcohol warning messages. As mentioned earlier, this study measured 1) the relationship between attitude estimates concerning reduction or moderation of alcohol consumption and differential attitudes toward alcohol warning messages, 2) the relationship between estimates of subjective norms concerning reduction or moderation of alcohol consumption and differential subjective norms (i.e., attitudes toward alcohol warning messages based on subjective norm), 3) the relationship between differential attitudes toward alcohol warning messages and differential intentions to switch alcohol consumption, 4) the relationship between differential subjective norms and differential intention to switch alcohol consumption, and 5) the relationship between differential intention to switch alcohol consumption and behavioral change to reduce or moderate alcohol consumption.

The results of this study indicated that alcohol warning messages significantly affected consumer attitudes toward reduction or moderation of alcohol consumption. The relationship between attitude estimates concerning reduction or moderation of alcohol consumption and differential attitudes toward alcohol warning messages was significantly positive. The relationship between estimates of subjective norms concerning reduction or moderation of alcohol consumption and differential subjective norms (i.e., attitudes toward alcohol warning messages based on subjective norms) was also significantly positive. Further, 1) the relationship between differential attitudes toward alcohol warning messages and differential intention to switch alcohol consumption was significantly positive, 2) the relationship between differential subjective norm and differential intention to switch alcohol consumption was significantly positive, and 3) the relationship between differential intentions to switch alcohol consumption and behavioral changes to reduce or moderate alcohol consumption was significantly positive. Also, the effects of differential attitude on differential intention were stronger than the effects of differential subjective norm on differential intention. Additionally, this study measured 1) the effects of attitudes on differential attitudes and 2) the effects of estimates of subjective norms on differential subjective norms with different types of warning messages. The findings of these additional tests indicated that the perceptions of different types of alcohol warning messages were significantly different. The effects of attitude estimates on attitudes toward alcohol warning messages varied depending on whether alcohol warning messages addressed positive or negative reinforcement, one-sided or twosided messages, and self-related and other-related issues. The effects of estimates of subjective norms on attitudes toward alcohol warning messages were also different depending on types of alcohol warning messages, whether messages addressed positive or negative reinforcement, one-sided message or two-sided message, and self-related or 
others-related issues. With respect to the effects of estimates of subjective norms on attitude toward alcohol warning messages, this paper has demonstrated that the effects of estimates of subjective norms on attitudes toward alcohol warning messages that addressed other-related issues were more significant than others.

Many of the participants, however, perceived that the exposure level of alcohol warning messages was low. Only $2 \%$ of respondents mentioned that they often saw alcohol warning or moderation messages. Given that alcohol warning messages positively affected consumer attitudes toward reduction or moderation of alcohol consumption, government agents and other parties need to revise the current regulations concerning alcohol consumption to enhance effectiveness. They should study various types of alcohol warning messages and try to increase the exposure level of alcohol warning messages effectively. Overall, working out the managerial implications for alcohol warning and advertising polices is significantly needed as part of most important long-term plans of public policy issues.

Despite these findings, there remain some limitations to this study. First, no detailed causal analysis was conducted. This issue should be considered in future research. The findings of this study may not match those conducted in other countries with people of different cultural backgrounds. In order to draw more general results, similar surveys should be conducted in various other nations in future studies. The study used qualitative research, while it was not conducted for hypotheses testing. It would also be useful to investigate attitudes toward alcohol warning messages by increasing the size of literature and also by applying more in-depth approaches. Therefore, comparing results from both qualitative and quantitative research might provide interesting and meaningful results. In further studies, more subjects and issues will need to be studied.

\section{ACKNOWLEDGEMENT}

The author is grateful for the financial support from the KDI School of Public Policy and Management.

\section{AUTHOR INFORMATION}

Yoon C. Cho received MBA from Cornell and Ph.D. in Management from Rutgers University. She was associate professor at Hawaii Pacific University and currently professor at the KDI School of Public Policy and Management, Seoul, Korea. Send correspondence to Prof. Yoon C. Cho, KDI School of Public Policy and Management, 85 Hoegiro, Dongdaemun Gu, Seoul, Korea, Tel: +82-2-3299-1087. E-mail: ycho@kdischool.ac.kr, yoonji22e@gmail.com (Corresponding author)

Jihon Rim received MBA from the KDI School of Public Policy and Management and is currently an employee at a health care company, Infopia.

\section{REFERENCES}

1. Aaker, David A., and Mayers, John G. (1987), Advertising Management, Englewood Cliffs, NJ: PrenticeHall, Inc.

2. Ajzen, Icek, and Fishbein, Martin (1980), Understanding Attitudes and Predicting Social Behavior, New Jersey: Prentice-Hall.

3. Allen, Chris T., and Madden, Thomas J. (1985), “A Closer Look at Classical Conditioning," Journal of Consumer Research, Vol. 12, pp. 301-15.

4. Andrews, J. Craig, Netemeyer, Richard G., and Durvasula, Srinivas (1990), "Believability and Attitudes Toward Alcohol Warning Label Information: The Role of Persuasive Communications Theory," Journal of Public Policy and Marketing, Vol. 9, Issue 1, pp. 1-15.

5. Apter, Michael J. (1989) Reversal Theory, New York and London: Routledge.

6. Bettman, James R, Payne, John W., and Staelin, Richard (1986), "Cognitive Considerations in Designing Effective Labels for Presenting Risk Information,” Journal of Public Policy and Marketing, Vol. 5, pp. 1-28.

7. Cho, Yoon C. (2010), "An Analysis of Customer Expectations/Dissatisfaction toward Perishable Grocery Goods in the Online Environment," 2010 Global marketing conference at Tokyo: "Innovation, Diffusion, and Adoption of High Technology Products/Services" Track. 
8. Clark, Eddie M., and Brock, Timothy C. (1994), "Warning Label Location. Advertising, and Cognitive Responding," in Attention, Attitude, and Affect in Response to Advertising, Clark, E. M., Brock, T. C., and Stewart, D. W, eds. Hillsdale, NJ: Lawrence Erlbaum Associates.

9. Clee, Mona A. and Wicklund, Robert A. (1980), "Consumer Behavior and Psychological Reactance," Journal of Consumer Research, Vol. 6(March), pp. 389-405.

10. Cobuild (2001), Collins Cobuild Dictionary, Westerhill Road, Bishopbriggs: HarperCollins Publishers.

11. Cuniz (1981), Psychologically Effective Warnings.

12. Doubleday (1975), Doubleday Dictionary, Garden City, NY: Doubleday and Company.

13. Feingold, P.C., and Knapp, M.L. (1977), “Anti-drug abuse commercials,” Journal of Communication, Vol. 27, pp.20-28.

14. Graves, Karen L. (1993), “An Evaluation of the Alcohol Warning Label: A Comparison of the United States and Ontario, Canada in 1990 and 1991," Journal of Public Policy and Marketing, Vol.12, Issue 1, pp. 19-29.

15. Grossman, Randi Priluck, and Till, Brian D. (1998), "The Persistence of Classically Conditioned Brand Attitude," Journal of Advertising, Vol. 27, Issue 1, pp. 23-31.

16. Hilton, Michael E. (1993), "An Overview of Recent Findings on Alcoholic Beverage Warning Labels," Journal of Public Policy and Marketing, Vol. 12, Issue 1, pp. 1-9.

17. Jernigan, D.H. (1997), Thirsting for markets: the global impoact of corporate alcohol, San Rafael: Marin Institute for the Prevention of Alcohol and Other Drug Problems.

18. Kamins, Michael A. and Assael, Henry (1987), "Two-Sided Versus One-Sided Appeals: A Cognitive Perspective on Argumentation, Source Derogation, and the Effect of Disconfirming Trial on Belief Change," Journal of Marketing Research, Vol.24, February, pp. 29-39.

19. Malouff, John, Schutte, Nicola, Wiener, Kimara, Brancazio, Christine, and Fish, Darla (1993), "Important Characteristics of Warning Displays on Alcohol Containers," Journal of Studies on Alcohol, Vol. 54, Issue 4, pp. 457-61.

20. Mayer, Robert N., Smith, Ken R., and Scammon, Debra L. (1991). "Evaluating the Impact of Alcohol Warning Labels," Advances in Consumer Research, Vol. 18, pp. 706-14.

21. Mazis, Michael B., Morris, Louis A., and Swasy John L. (1991), “An Evaluation of the Alcohol Warning Label: Initial Survey Results,” Journal of Public Policy and Marketing, Vol. 10, Issue 1, pp. $229-41$.

22. Mcsweeney, Frances K., and Bierley, Calvin (1984), "Recent Developments in Classical Conditioning," Journal of Consumer Research, Vol. 11, pp. 619-31.

23. Ogivly, David (1985), Ogivly on Advertising, New York: Random House.

24. O’Shaughnessy, John, and O'Shaughnessy Nicholas Jackson (2007), Persuasion in Advertising, New York: Routledge.

25. Pechmann Cornelia (1992), "Predicting When Two-Sided Ads Will be More Effective Than One-sided Ads: The Role of Correlational and Correspondent Inferences," Journal of Marketing Research, Vol. 29, pp. 44153.

26. Petty, Richard, and Cacioppo, John (1986), Communication and Persuasion: Central and Peripheral Routes to Attitude Change. New York: Springer-Verlag.

27. Ross, Kenneth (1981), "Legal and Practical Considerations for the Creation of Warning Labels and Instruction Books," Journal of Products Liability, Vol. 4, Issue 1, pp. 29-45.

28. Scammon, Debra L., Mayer, Robert N., and Smith, Ken R. (1991), “Alcohol Warnings: How Do You Know When You Have Had One Too Many?” Journal of Public Policy and Marketing, Vol. 10, Issue 1, pp. 21418.

29. Settle, Robert B., and Golden, Linda L. (1974), “Attribution Theory and Advertiser Credibility,” Journal of Marketing Research, Vol. 11, pp. 181-5.

30. Skinner, B.F. (1953), Science and Human Behavior, New York: Free Press.

31. Sirgy, Joseph M. (1982), "Self-Concept in Consumer Behavior: A Critical Review," Journal of Consumer Research, Vol.9, December, pp. 287-300.

32. Smith, Robert E., and Hunt, Shelby D. (1978), “Attributional Processes and Effects in Promotional Situations," Journal of Consumer Research, Vol. 5, pp. 149-58.

33. Smith, Sandra J. (1990), "The Impact of Product Usage Warnings in Alcoholic Beverage Advertising," Journal of Public Policy \& Marketing, Vol. 9, Issue 1, pp. 16-29. 
34. Snyder, Lesile B., and Blood, Deborah J. (1991), "Alcohol Advertising and The Surgeon General's Alcohol Warnings May Have Adverse Effects on Young Adults," presented to the International Communication Association Annual Conference, Chicago (May).

35. Solomon, Michael R. (2008), Consumer behavior: buying, having, and being, $8^{\text {th }}$ ed., New Jersey: Pearson Prentice Hall

36. Stayman, Douglas, Hoyer, Wayne, and Leon, Robert (1987), "Attribute Importance in Discounting Product Features in Advertising," paper presented at American Marketing Association, Summer Educators' Conference, Toronto.

37. Stewart, David W., and Martin, Ingrid M. (1994), "Intended and Unintended Consequences of Warning Messages: A Review and Synthesis of Empirical Research," Journal of Public Policy \& Marketing, Vol. 13, Issue 1, pp. 1-19.

38. Stuart, Elnora W., Shimp, Terence A., and Engle, Randall W. (1987), "Classical Conditioning of Consumer Attitudes: Four Experiments in an Advertising Context," Journal of Consumer Research, Vol. 14, pp. 33449.

39. Taylor, D.H. (1976), “Accidents, Risks, and Models of Explanation,” Human Factors, Vol. 18, pp. 371-80.

40. Torres, Ivonne M., Sierra, Jeremy J., and Heiser, Robert S. (2007), "The effects of warning-label placement in print Ads," Journal of Advertising, Vol. 36, Issue 2, pp. 49-62.

41. Wilkinson, Claire, and Room, Robin (2009), "Warnings on alcohol containers and advertisements: International experience and evidence on effects," Drug and Alcohol Review, Vol. 28, pp. 426-35.

42. Wogalter, Michael S., and Laughery, Kenneth R. (1996), "Warning! Sign and Label Effectiveness," Current Directions in Psychological Science, Vol. 5, Issue 2, pp. 33-37. 


\section{NOTES}

